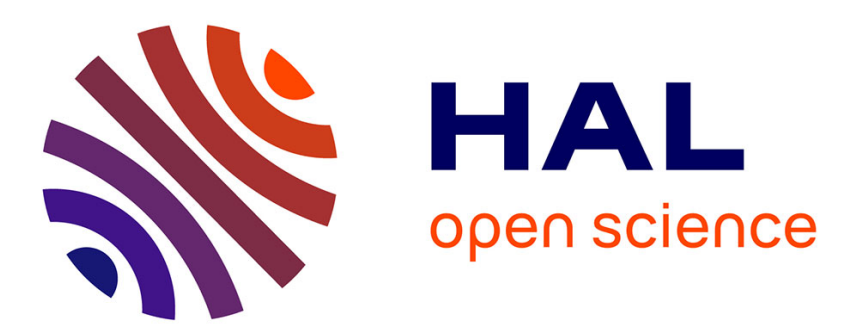

\title{
Choice of control law in electropneumatics. Expertise using an industrial benchmark and some new trends
}

\author{
Xavier Brun, Daniel Thomasset
}

\section{To cite this version:}

Xavier Brun, Daniel Thomasset. Choice of control law in electropneumatics. Expertise using an industrial benchmark and some new trends. 39th IEEE CDC, Dec 2000, Sydney, Australia. pp.13231328, 10.1109/CDC.2000.912040 . hal-02064140

\section{HAL Id: hal-02064140 \\ https://hal.science/hal-02064140}

Submitted on 20 Mar 2019

HAL is a multi-disciplinary open access archive for the deposit and dissemination of scientific research documents, whether they are published or not. The documents may come from teaching and research institutions in France or abroad, or from public or private research centers.
L'archive ouverte pluridisciplinaire HAL, est destinée au dépôt et à la diffusion de documents scientifiques de niveau recherche, publiés ou non, émanant des établissements d'enseignement et de recherche français ou étrangers, des laboratoires publics ou privés. 


\title{
CHOICE OF CONTROL LAW IN ELECTROPNEUMATICS. EXPERTISE USING AN INDUSTRIAL BENCHMARK AND SOME NEW TRENDS.
}

\author{
X. BRUN and D. THOMASSET \\ Laboratoire d'Automatique Industrielle \\ http://www.insa-lyon.fr/Laboratoires/lai.gb.html \\ INSA Lyon, Bâtiment Saint Exupéry \\ 23 Avenue Jean Capelle, 69621 Villeurbanne Cedex, FRANCE \\ Tel: (33) $472438881 \quad$ Fax: (33) 472438535 \\ e-mail : xavier.brun@ lai.insa-lyon.fr / daniel.thomasset@lai.insa-lyon.fr
}

Keywords: Linear and nonlinear control, Flatness, Fluid Power, Industrial application.

\begin{abstract}
The aim of this paper is to propose help for choosing a control strategy to certain specifications. The system under study is an electropneumatic actuator. Different kinds of linear and nonlinear control laws have been developed and experimental results have been analyzed and compared in accordance with appropriate benchmarking. Moreover some new trends are presented. They show the interest of a multi-input control law in terms of stability and energy consumption due to the flatness property.
\end{abstract}

\section{Introduction}

For the last twenty years, the parallel development of pneumatic systems and control theory has lead to the implementation of modern control laws in pneumatic devices [Edge 1997]. However the complexity of the electropneumatic systems and the important range of control laws are a real industrial problem where the target is to choose the best strategy for a given application. Nowadays the control procedure is included in sizing. It is important to know which kind of control law will be used to help choosing the appropriate equipment. Unfortunately this step is often omitted and the choice is reduced to selecting the value of the P.I.D. gains. It known, however, that these control law, which is very efficient for many processes, does not give good performances for electropneumatic systems. The presence of an integral term is one of the possible causes of the undesirable sticking [Drakunov 1997] and restarting phenomenon [Brun 1999a]. So in aiming to help the manufacturer of electropneumatic processes, or people who have to choose a control strategy for a given requirement, we propose to compare classical linear control laws and sophisticated nonlinear laws with same equipment. After a description of the physical electropneumatic system on which the different control laws have been implemented, a mathematical model of the process is given. Experimental results are presented in terms of repeatability: standard deviation, mean value, maximum error... A benchmarking is carried out to show main drawbacks and advantages of each studied control laws. In the last section for the first time, the flatness approach is used in an electropneumatic system, in order to reduce the energy consumption.

\section{The electropneumatic system}

\section{Notations}

$f_{v} \quad$ viscous friction coefficient $\quad[\mathrm{N} / \mathrm{m} / \mathrm{s}]$

$F_{\text {ext }} \quad$ external force

$[\mathrm{N}]$

$k \quad$ polytropic constant

$M \quad$ total moving load mass [kg]

$p_{X} \quad$ pressure in chamber $\mathrm{X} \quad[\mathrm{Pa}]$

$p_{S}, p_{E} \quad$ supply and exhaust pressures [Pa]

$r \quad$ perfect gas constant [J/kg/K]

$S_{P}, S_{N} \quad$ piston areas $\quad\left[\mathrm{m}^{2}\right]$

$T_{X}, T_{S} \quad$ chamber $\mathrm{X}$ and ambient temperatures [K]

$u_{P}, u_{N}$ servo-distributor voltages [V]

$V_{X} \quad$ volume of chamber $\mathrm{X} \quad\left[\mathrm{m}^{3}\right]$

$V_{D X} \quad$ dead volume of chamber $X \quad\left[\mathrm{~m}^{3}\right]$

$V_{X}(0) \quad$ piped vol. of chamber $\mathrm{X}$ for zero position $\left[\mathrm{m}^{3}\right]$

$y^{C} \quad$ central position : $V_{P}\left(y^{c}\right)=V_{N}\left(y^{c}\right) \quad[\mathrm{m}]$

$y, v, a \quad$ position, velocity, acceleration $[\mathrm{m}],[\mathrm{m} / \mathrm{s}],\left[\mathrm{m} / \mathrm{s}^{2}\right]$

$K_{y}, K_{v}, K_{a}$ position, velocity, acceleration feedback gains $[\mathrm{V} / \mathrm{m}],[\mathrm{V} / \mathrm{m} / \mathrm{s}],\left[\mathrm{V} / \mathrm{m} / \mathrm{s}^{2}\right]$

$j \quad$ jerk (acceleration derivation) $\left[\mathrm{m} / \mathrm{s}^{3}\right]$ 
$q_{m} X$ mass flow rates provided from the servodistributor to the cylinder chamber $\mathrm{X} \quad[\mathrm{kg} / \mathrm{s}]$ $\delta \quad$ variation near the equilibrium set

$\bar{\varepsilon}, \mathcal{\varepsilon}, \sigma \quad$ mean error, static error, standard deviation[mm] $\mathrm{H}, \quad$ heat transfer $\quad[\mathrm{J} / \mathrm{s}]$ $\mathrm{dW}_{\text {MECA }}, \mathrm{dQ}$ mechanical work, heat transfer $[\mathrm{J} / \mathrm{s}]$ $d \quad$ desired trajectory

The system under consideration is an in line electropneumatic servodrive, controlled by two threeway servo-distributors, as shown on figure $\mathbf{1 .}$

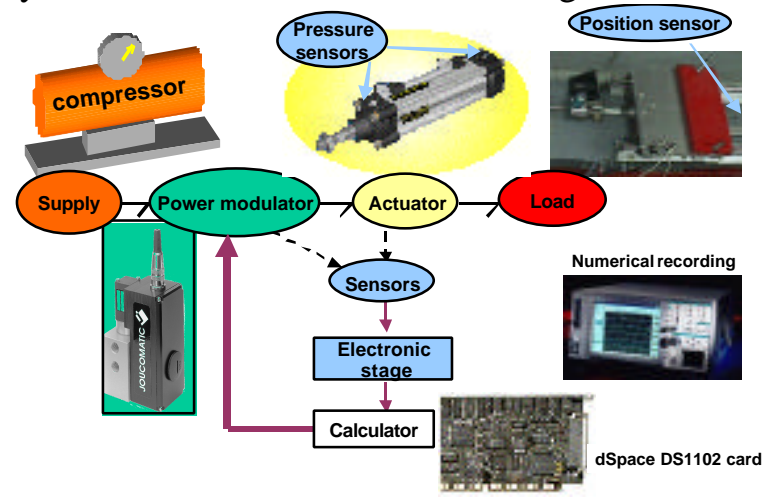

Figure 1: Principle of electropneumatic system.

The electropneumatic system model can be obtained using three physical laws: the mass flow rate through a restriction, the pressure behavior in a chamber with variable volume and the fundamental mechanical equation. In our case, the bandwidth of the Servotronic Joucomatic Servo-distributor and the actuator are respectively about $200 \mathrm{~Hz}$ and 2,4 Hz. Using the singular perturbation theory, the faster dynamic can be neglected. The pressure evolution law in a chamber with variable volume is obtained assuming the following assumptions [Shearer 1956]. Air is a perfect gas and its kinetic energy is negligible. The pressure and the temperature are homogeneous in each chamber. The process is polytropic and characterized by coefficient $k$. The dry friction is neglected. Moreover, the electropneumatic system model is obtained by combining all the previous relations and assuming that the temperature variation is negligible with respect to average and equal to the supply temperature. So the following relation gives the model of the system above:

$$
\left\{\begin{array}{l}
\frac{d p_{P}}{d t}=\frac{k r T_{s}}{V_{P}(y)}\left[q_{m}\left(u_{P}, p_{S}, p_{E}, p_{P}\right)-\frac{S_{P}}{r T_{s}} p_{P} v\right] \\
\frac{d p_{N}}{d t}=\frac{k r T_{s}}{V_{N}(y)}\left[q_{m^{N}}\left(u_{N}, p_{S}, p_{E}, p_{N}\right)+\frac{S_{N}}{r T_{s}} p_{N} v\right] \\
\frac{d v}{d t}=\frac{1}{M}\left[S_{P} p_{P}-S_{N} p_{N}-f_{v} v-F_{e x t}\right] \\
\frac{d y}{d t}=v
\end{array}\right.
$$

$$
\text { where }\left\{\begin{array} { l } 
{ V _ { P } ( y ) = V _ { P } ( 0 ) + S _ { P } y } \\
{ V _ { N } ( y ) = V _ { N } ( 0 ) - S _ { N } y }
\end{array} \text { and } \left\{\begin{array}{l}
V_{P}(0)=V_{D P}+S_{P} \frac{\text { Stoke }}{2} \\
V_{N}(0)=V_{D N}+S_{N} \frac{\text { Stoke }}{2}
\end{array}\right.\right.
$$

The main difficulty for model (1) is to know the mass flow rates $q_{m} P$ and $q_{m}{ }$. This model is issue of experimental measurement [Sesmat 1996] and therefore a mathematical model for a static flow stage has been obtained from a polynomial approximation [Belgharbi 1999] with the following form:

$q_{m}\left(u_{X}, p_{X}\right)=\varphi\left(p_{X}\right)+\psi\left(p_{X}, \operatorname{sgn}\left(\Gamma\left(u_{X}\right)\right)\right) \times \Gamma\left(u_{X}\right)$

For linear control, the input signal is used and sent with opposite signs to both servo-distributors:

$u_{P}=-u_{N}=u$

Also the electropneumatic model is in the nonlinear affine form:

$$
\begin{array}{ccc}
\underline{x} & =f(\underline{x})+g(\underline{x}) \times U \quad \text { with } & U=\Gamma(u) \\
\underline{x} & =\left[\begin{array}{c}
p_{P} \\
p_{N} \\
v \\
y
\end{array}\right] f(\underline{x})=\left(\begin{array}{c}
\frac{k r T_{s}}{V_{P}(y)}\left[\varphi\left(p_{P}\right)-\frac{S_{P}}{r T_{s}} p_{P} v\right. \\
\frac{k r T_{s}}{V_{N}(y)}\left[\varphi\left(p_{N}\right)+\frac{S_{N}}{r T_{s}} p_{N} v\right] \\
\frac{1}{M}\left[S_{P} p_{P}-S_{N} p_{N}-b v-F_{e x}\right] \\
v
\end{array}\right) g(\underline{x})=\left(\begin{array}{c}
\frac{k r T_{s}}{V_{P}(y)} \psi\left(p_{P}, \operatorname{sgn}(U)\right) \\
-\frac{k r T_{s}}{V_{N}(y)} \psi\left(p_{N}, \operatorname{sgn}(-U)\right) \\
0 \\
0
\end{array}\right)
\end{array}
$$

The equilibrium set is defined by $\dot{x}=f\left(x^{e}, u^{e}\right)=0$. A procedure to obtain the linearized model is given in [Brun 1999b].

\section{Industrial benchmark}

From nonlinear and linear models different kinds of control laws can be synthesized. Two linear laws were presented in [Brun 1999b] and compared. A nonlinear one is developed in the following section.

From an industrial or academic point of view, the presentation of experimental results is a very delicate stage. All interpretations have to be checked by many experiments. Some phenomenon are stochastic and simulation is a good way to understand their physical behavior. That is why all tests are carried out one hundred times, in similar conditions (as far as possible), with the aim of extracting mean, maximum and minimum values, standard deviation, root mean square... These statistics are presented in a table and some graphs are shown.

All retained criteria correspond to important objectives, which are generally presented in the requirements. The improvements and drawbacks of some control strategies are also presented. Two kinds of family criteria are defined. The first one concerns physical criteria such as accuracy, repeatability, maximum velocity or acceleration... The second is economic criteria, the goal is to present the number of sensors, the complexity of implementation and the coast to maintain.

So eleven criteria have been accepted. The mean static error, the standard deviation, the frequency of 
an undesirable occurrence: the sticking and restarting phenomenon [Brun 1999a], the number of sensors, the synthesis complexity, the adjustment complexity. Three statistics concern only point to point desired position: the time constant around mid-stroke displacement, the time constant near end-stroke displacement, the maximum velocity,

Two last values only concern tracking objectives: the tracking error in position, the tracking error in velocity.

\section{Nonlinear control law in tracking}

A convenient way to linearize model (6) for every position of the cylinder stroke is to use the nonlinear linearizing control law [Isidori 1989], which theoretically transforms the closed loop system into two parts. The first part consists of a cascade of $\rho$ integrators and the second is an unobservable subsystem of dimension $(n-\rho)$ ) $\rho$ is the relative order of the output, $n$ is the system order). The single output is the position: $h(\underline{x})=y$

A simple calculation shows that for the system under study, the characteristic number is equal to three. In the single input output case, the linearizing nonlinear control is given by:

$$
\begin{aligned}
& U=\frac{1}{L_{g} L_{f}^{2} h}\left(-L_{f}^{3} h+w\right) \text { with } \\
& \left\{\begin{array}{l}
L_{f}^{3} h=\frac{S_{P}}{M} \frac{k r T_{s}}{V_{P}(y)}\left[\varphi\left(p_{P}\right)-\frac{S_{P}}{r T_{s}} p_{P} v\right]-\frac{S_{N}}{M} \frac{k r T_{s}}{V_{N}(y)}\left[\varphi\left(p_{N}\right)+\frac{S_{N}}{r T_{S}} p_{N} v\right] \\
L_{g} L_{f}^{2} h=\frac{S_{P}}{M} \frac{k r T_{S}}{V_{P}(y)} \psi\left(p_{P}, s g n(U)\right)+\frac{S_{N}}{M} \frac{k r T_{s}}{V_{N}(y)} \psi\left(p_{N}, s g n(-U)\right)
\end{array}\right.
\end{aligned}
$$

It is important to note that $L_{g} L_{f}^{2} h$ is always strictly positive. So $U$ has the same sign as $\left(-L_{f}^{3} h+w\right)$. By definition, $w$ and $L_{f}^{3} h$ are independent of $U$ (see relations 7 and 8). Consequently, the control law is not implicit. This remark explains the choice of the function $\varphi$, independent of $U$, in the mass flow rate expression of equation 3 .

The second feedback law, which fixes the dynamic behavior of the state tracking errors, is obtained with the reference model:

$$
w=j^{d}-K_{y}\left(y^{d}-y\right)-K_{v}\left(v^{d}-v\right)-K_{a}\left(a^{d}-a\right)
$$

The nonlinear control applied to the system is shown in figure $\mathbf{2}$ and may be written as in equation 9 .

$u=\Gamma^{-1}\left(\frac{1}{L_{g}^{2} L_{f}^{2} h}\left(-L_{f}^{3} h+j^{d}-K_{y}\left(y^{d}-y\right)-K_{v}\left(v^{d}-v\right)-K_{a}\left(a^{d}-a\right)\right)\right)(9)$ The validity of the control law depends on the stability of the unobservable subsystem of dimension one. Today we are not able to prove the global stability of the residual dynamic but in the physical domain the local stability has been demonstrated [Brun 1999c].

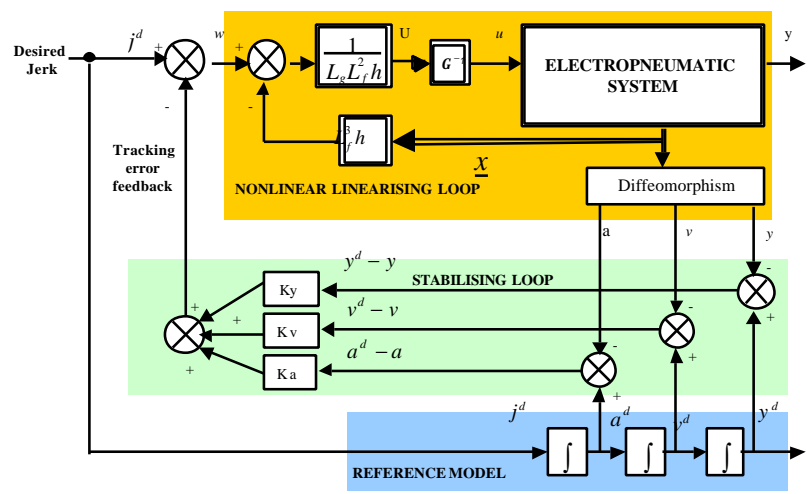

Figure 2: Principle of nonlinear tracking control.

\section{Control law expertise}

The results are presented qualitatively and not quantitatively. Table 1 resumes and compares the state feedback control laws with fixed and scheduled gains [Brun 1999b] for point to point displacement and also the linear and nonlinear control laws for tracking objectives. Advantages are presented with "+" symbols and the drawbacks appears with the symbol "-".

For partial feedback of position, velocity and acceleration, only one position sensor is used. The velocity is reconstructed by analog derivation and this signal is numerically derived to obtain the acceleration.

\subsection{Point to point case study at the extremity}

The figure 3 shows the behavior of the load for a displacement equal to $10 \%$ of the total stroke, obtained near the extremity. The improvement due to scheduled gains is about $40 \%$ in term of response time. Moreover the static error is, in this figure, five times less but the phenomenon of sticking and restarting appears with the both control strategies. The main drawback of the control law with scheduled gains is its complexity to elaborate. In fact, the values of the gains have to be calculated for every position of the cylinder. So we need to establish the tangent linearized model for many points of the equilibrium set. Then, the gain function is obtained by interpolation and approximation by the least square method.

Thus this more sophisticated method must be used when good performances are required at the cylinder ends. 


\begin{tabular}{|c|c|c|c|c|}
\hline Desired position & \multicolumn{2}{|c|}{ Point to point } & \multicolumn{2}{|c|}{ Tracking } \\
\hline Control law & $\begin{array}{l}\text { State feedback } \\
\text { with fixed gains }\end{array}$ & $\begin{array}{c}\text { State feedback } \\
\text { with scheduled } \\
\text { gains }\end{array}$ & Linear control & Nonlinear control \\
\hline Static error & + & ++ & + & + \\
\hline Tracking error in position & \multirow{2}{*}{\multicolumn{2}{|c|}{. }} & + & ++ \\
\hline Tracking error in velocity & & & ++ & ++ \\
\hline Response time around the mid-stroke & + & + & & \\
\hline Response time near the end-stroke & ++ & +++ & & \\
\hline Maximum velocity & + & ++ & & \\
\hline Standard deviation & + & +++ & + & ++ \\
\hline Sticking and restarting phenomenon & -- & - & -- & + \\
\hline Number of sensor(s) & 1 & 1 & 1 & 3 \\
\hline Synthesis complexity & ++ & - & + & - - \\
\hline Adjustment complexity & + & + & + & + \\
\hline
\end{tabular}

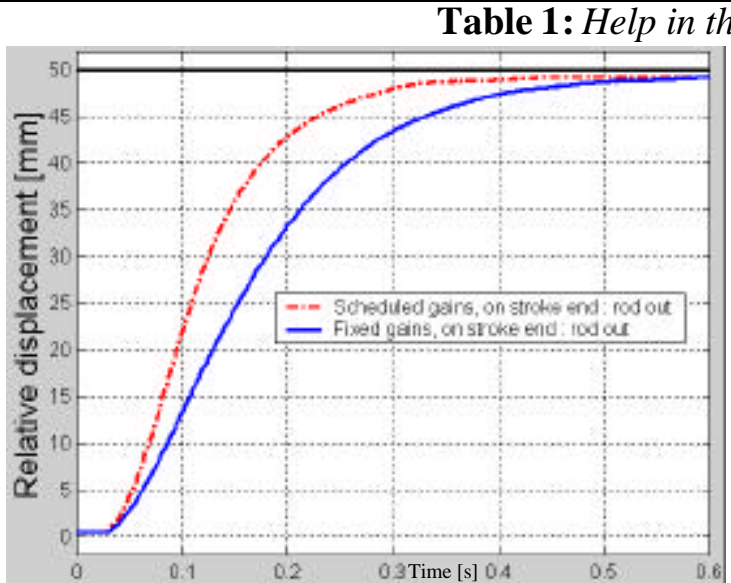

a- total relative displacement

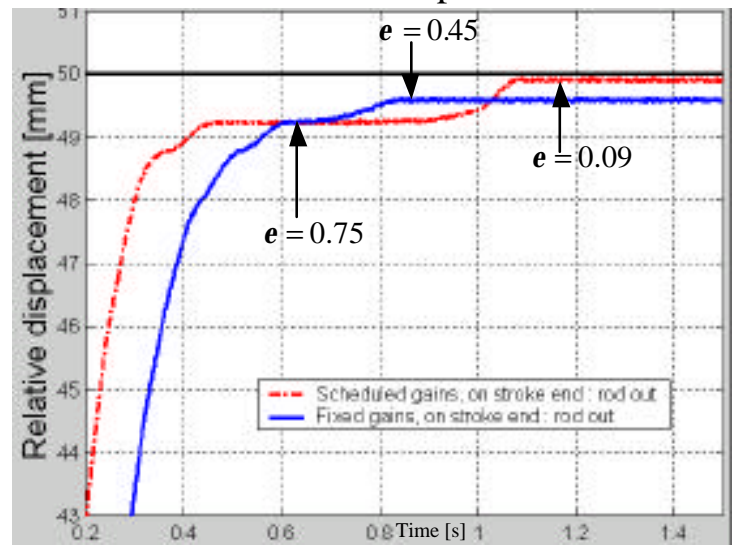

b- zoom near the end stroke

Figure 3: Step response with scheduled and fixed gains near the stroke extremity.

\subsection{Trajectory tracking case study}

Different kinds of trajectories have been experimentally tested. Figures $\mathbf{4}$ and $\mathbf{5}$ show respectively the error in position obtained with linear and nonlinear control laws during the rod out. The main characteristics of the desired trajectory are resumed in table $\mathbf{2}$. The amplitude of the movement is equal $90 \%$ of the total stroke, the trajectory is symmetrical and admissible by the system under consideration [Brun 1999c].

\begin{tabular}{|l|c|}
\hline Amplitude of movement [mm] & 400 \\
\hline Sampling period [ms] & 4 \\
\hline Duration of rod out [s] & 2.040 \\
\hline Duration of one cycle [s] & 9.996 \\
\hline Duration with constant jerk [ms] & 60 \\
\hline Duration with constant acceleration [ms] & 900 \\
\hline Duration with constant velocity [ms] & 0 \\
\hline Maximum velocity [m/s] & 0.39 \\
\hline Maximum acceleration [m/s $\mathrm{s}^{2}$ ] & 0.41 \\
\hline Maximum jerk [m/s ${ }^{3}$ ] & 6.8 \\
\hline
\end{tabular}

Table 2: Main characteristics of the desired trajectory. In terms of repeatability, the results are shown in figure 4. For a gaussian distribution, the envelope delimited by mean error plus or minus standard deviation includes $68 \%$ of the cases.

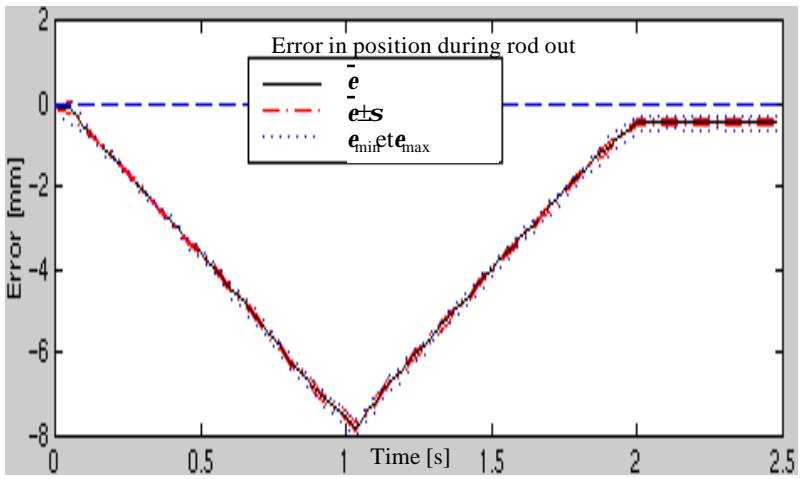

Figure 4: Error in position with linear control law

For this trajectory with constant acceleration and deceleration stages, the improvement in terms of repeatability due to the nonlinear structure is about $20 \%$. This improvement is obtained thanks to the nonlinear structure. Moreover it is very important to notice that this strategy of control law inhibits the sticking and restarting phenomenon, which is very important for the development of electropneumatic systems. These two very good results are not obtained without cost. In fact, to linearize the model in every position, the drawbacks concern the utility of two 
pressure sensors, and the complexity to synthesize the control law.

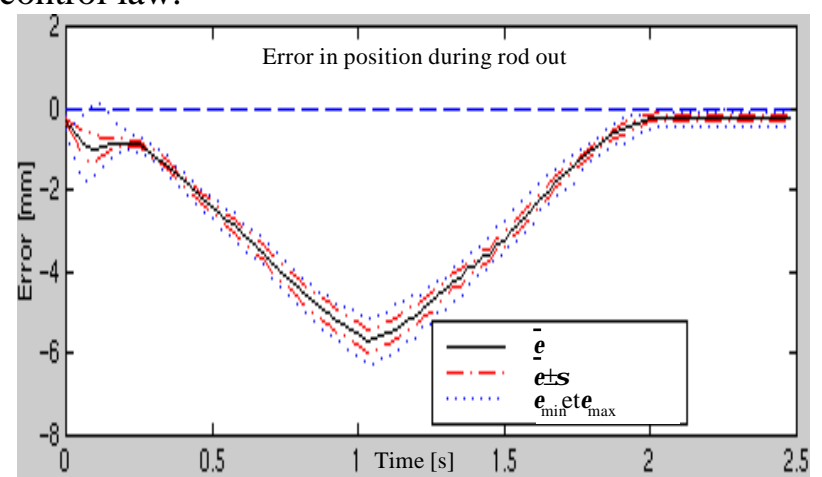

Figure 5: Error in position with nonlinear control law

\section{Interest of multivariable control law}

\subsection{Flatness properties}

With two inputs $u_{P}$ and $u_{N}$, the model given by equation 6 has the form $\underline{\dot{x}}=f(\underline{x})+G(\underline{x}) \underline{U}$ with the same vector $f$ and $G(\underline{x})$ and $\underline{U}$ are given by equation 10.

$$
\begin{gathered}
G(\underline{x})=\left(g_{1}(\underline{x}) g_{2}(\underline{x})\right)=\left(\begin{array}{cc}
\frac{k r T_{S}}{V_{P}(y)} \psi\left(p_{P}, s g n\left(U_{P}\right)\right) & 0 \\
0 & -\frac{k r T_{S}}{V_{N}(y)} \psi\left(p_{N}, s g n\left(U_{N}\right)\right) \\
0 & 0 \\
0 & 0
\end{array}\right) \\
\underline{U}=\left(\begin{array}{c}
U_{P} \\
U_{N}
\end{array}\right)=\left(\begin{array}{c}
\Gamma\left(u_{P}\right) \\
\Gamma\left(u_{N}\right)
\end{array}\right)
\end{gathered}
$$

The two chosen outputs are the pressure in chamber $P$ and the position:

$$
h(\underline{x})=\left(\begin{array}{c}
h_{1}(\underline{x}) \\
h_{2}(\underline{x})
\end{array}\right)=\left(\begin{array}{c}
p_{P} \\
y
\end{array}\right)
$$

The characteristic number associated to the pressure $p_{P}$ and the position are respectively one and three. Thus, the sum is equal to the dimension of the system. This is sufficient to affirm that the system is differentially flat [Fliess 1995]. Due to the flatness definition, the inputs can be written as functions of outputs and a finite number (equal to the characteristic number) of their time derivatives. A direct way to obtain the nonlinear linearizing control laws which decouple the system consists in using the expressions of $d_{P}^{d} / d t$ and $j^{d}$ and inverting them.

The result is given by equation 12 . With the two previous control inputs $u_{P}$ and $u_{N}$, the nonlinear electropneumatic model is transformed into two linear models, one simple integrator and one triple integrator. Classic feedback laws can stabilize each of them. In this case the global stability is obvious. This is one of the main advantages of flatness.

$$
u_{P}=\Gamma^{-1}\left[\frac{\frac{S_{P}}{r T_{S}} p_{P}^{d} v^{d}-\varphi\left(p_{P}^{d}\right)}{\psi\left(p_{P}^{d}, \operatorname{sgn}\left(U_{P}\right)\right)}+\frac{\frac{V_{P}\left(y^{d}\right)}{k r T_{S}}}{\psi\left(p_{P}^{d}, \operatorname{sgn}\left(U_{P}\right)\right)} w_{1}\right]
$$

$$
\begin{aligned}
u_{N}=\Gamma^{-1}\left[-\frac{\frac{S_{N}}{r T T_{S}} p_{N}^{d} v^{d}+\varphi\left(p_{N}^{d}\right)+\frac{V_{N}\left(y^{d}\right)}{k r T S} \frac{b}{S_{N}} a^{d}}{\psi\left(p_{N}^{d}, \operatorname{sgn}\left(U_{N}\right)\right)}\right. \\
\left.+\frac{\frac{V_{N}\left(y^{d}\right)}{k r T S}}{\psi\left(p_{N}^{d}, \operatorname{sgn}\left(U_{N}\right)\right)}\left(-\frac{S_{P}}{S_{N}} w_{1}+\frac{M}{S_{N}} w_{2}\right)\right]
\end{aligned}
$$

$$
\text { With } p_{N}^{d}=\frac{1}{S_{N}}\left(S_{P} p_{P}^{d}-b v^{d}-F_{\text {ext }}-M a^{d}\right)
$$

\subsection{Simulated results}

The two nonlinear control laws have been implemented and tested with industrial specialized software: AMESim (Advanced Modeling Environment for performing Simulations of engineering systems). The power evolution during one position cycle with the two different control laws is shown in figure 6. In both cases it is important to remark that the efficiency is very low. Bachmann and Surgenor [Bachmann 1997] who considered adiabatic systems and obtained a partial efficiency of $9.4 \%$ have already noticed this characteristic of pneumatic systems. In the present case, considering heat exchanges, the efficiency is equal to $3.7 \%$ for the simple input system and $6.2 \%$ for the multi-input system. However, the most important value concerns the pneumatic energy required to the air supply. It corresponds to the input enthalpy flow integral. In this example the value is reduced from $537 \mathrm{~J}$ to $325 \mathrm{~J}$ for one cycle with the proposed new nonlinear control. This improvement of $\mathbf{5 2 \%}$ corresponds to real gain. This significant progress is obtained without degradation of tracking results. Figure 7 shows the pressure trajectories for the two different controls. The chosen pressure trajectory in chamber $\mathrm{P}$ has the consequence of producing a pressure in chamber $\mathrm{N}$ that evolves between the supply and exhaust pressures. This is not the optimum solution. But for this case $p_{N}$ is always lower than both pressures obtained in simple input case and becomes near to $p_{E}$. The energy consumption is decreased.

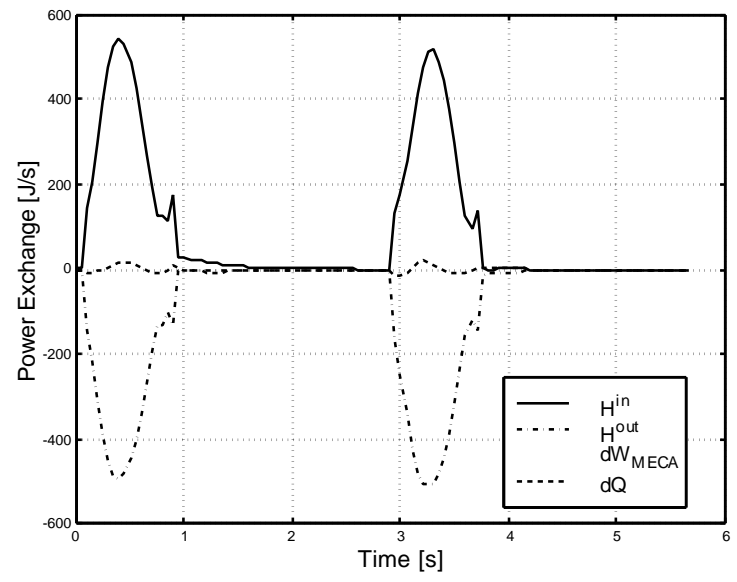

a- with simple input model 


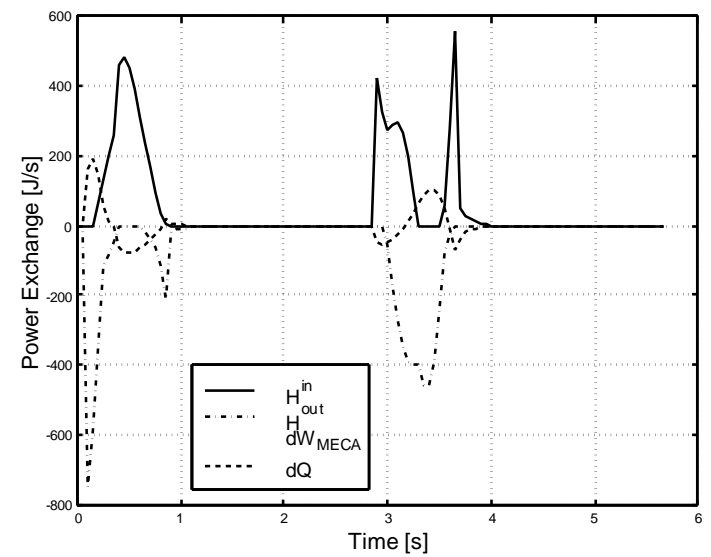

b- with multi-input model

Figure 6: Power variation during one cycle.

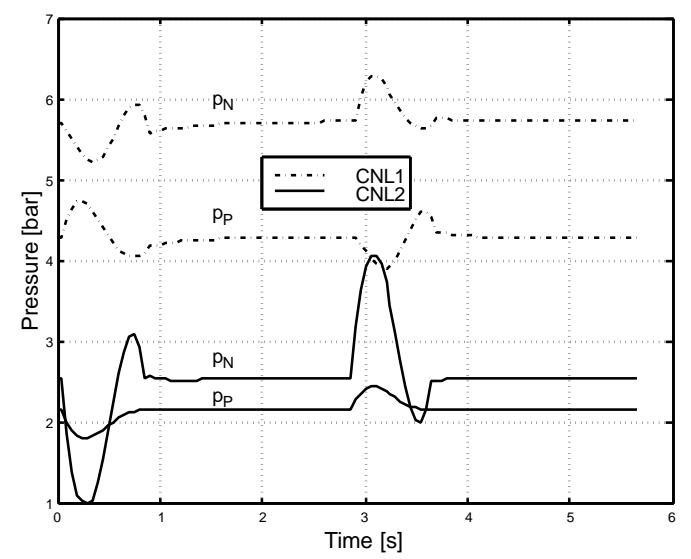

Figure 7: Pressure in chamber $P$ and $N$ with the two nonlinear controls.

\section{Conclusions}

After presenting a nonlinear and a tangent linearized model of an electropneumatic actuator, different control strategies have been studied. For both of them drawbacks and advantages have been presented, with the aim of helping the user to decide which one is appropriate for his application. Table $\mathbf{1}$ shows and resumes our main objective. It will be necessary to complete each column, with others control strategies, such as adaptive control, robust control (sliding mode, $\mathrm{H}_{8}$ ), fuzzy logic control, neural control ... and each row, with other comparison criteria such as efficiency, energy consumption, design ...etc.

In fact the proposed benchmarking is the result of a study in accordance with some industrial requirements but must evolve. As shown in the last row of table $\mathbf{1}$, the complexity of adjusting each control law is nearly the same. This characteristic is essential to enable the industrial transfer of sophisticated control laws. It is important to note that, for each case the gains that the user must choose correspond to fix the dynamic behavior of the process. So the value of these gains and the system properties are closely linked.
Since the early development of pneumatic actuators, the principle of control consists of filling one chamber with air and emptying the other. Energy is required to raise the pressure. Unfortunately nearly the same amount of energy is evacuated from the other chamber to the exhaust and less than $10 \%$ is transformed into mechanical energy, required for the displacement. Obviously, the energy consumption could be greatly reduced. Without changing the system design, it is showed in simulation that if another output is controlled, the efficiency can be increased and the consumption reduced. In this case we benefit of the flatness properties of the studied electropneumatic system. A similar approach has been study for hydraulic system [Bindel 1999] and seems to be interesting for large manipulator applications in weakly structured working environments, e. g. aircraft washing or shipbuilding.

\section{References}

[Edge 1997] Edge, K.A., 'The control of fluid power systems responding to the challenge. " Journal of Systems and Control Engineering, Vol 211, №12, p. 91-110, (1997).

[Drakunov 1997] Drakunov, S., Hanchin G.D., Su, W.C., Ozgüner, U. 'Nonlinear Control of a Roadless Pneumatic Servoactuator, or Sliding Modes versus Coulomb Friction", Automatica, Vol. 33, p 1401-1408, (1997).

[Brun 1999a] Brun, X., Sesmat, S., Scavarda, S., Thomasset, T., "Simulation and experimental study of the partial equilibrium of an electropneumatic positioning system, cause of the sticking and restarting phenomenon", $4^{\text {th }}$ JHPS Tokyo Japan,p125-130, (1999). [Shearer 1956] Shearer, J.L. "Study of pneumatic processes in the continuous control of motion with compressed air." Part I and II. Trans. Am. Soc. Mech. Eng., Vol. 78, p.233-249, (1956).

[Sesmat 1996] Sesmat, S., Scavarda, S. "Static characteristics of a three way servovalve." In: 12th Aachen Conf. on Fluid Power Technology, Aachen, Germany, p 643-652, March 12-13, (1996). [Belgharbi 1999] Belgharbi, M., Sesmat, S., Scavarda, S., Thomasset, D., "Analytical model of flow stage of an pneumatic Servo-distributor for simulation and nonlinear control." $6^{\text {th }}$ Scandinavian International Conference on Fluid Power, Tampere, Finland, p 847-860, May 26-28, (1999).

[Brun 1999b] Brun, X., Sesmat, S., Thomasset, T., Scavarda, S., "A comparative study between two control laws of an electropneumatic actuator", European Control Conference, Karlsruhe, Germany, [CD Rom], ref. F1000-5, (1999).

[Isidori 1989] Isidori, A., "Nonlinear control systems" $2^{\text {nd }}$ edition, New York : Springer Verlag, 479 p, (1989).

[Brun 1999c] Brun, X., Belgharbi, M., Sesmat, S., Thomasset, D., Scavarda, S., "Control of an electropneumatic actuator, comparison between some linear and nonlinear control laws", $J$. of Syst. and Control Eng., Vol. 213, NI5, p 387-406, (1999).

[Fliess 1995] Fliess, M., Lévine, J., Martin, Ph., Rouchon, P. "Flatness and defect of nonlinear systems: introductory theory and examples." Int. J. Control, Vol 61, p 1327-1361, (1995).

[Bachmann 1997] Bachmann, J.R., Surgenor, B.W. "On design and performance of a closed circuit pneumatic positioning system." The $5^{\text {th }}$ Scandinavian Int. Conference on Fluid Power, Linköping, Sweden, Vol.1, p 309-322, May 28-30, (1997).

[Bindel 1999] Bindel, R., Nitsche, R., Rothfuß, R., Zeitz, M., "Flatness based control of a two valve hydraulic joint actuator of a large manipulator", European Control Conference, Karlsruhe, Germany, [CD Rom], ref. F1009-2, (1999). 